\title{
APARELHO DE SUCÇÃO TIPO ASPIRADOR PARA CAPTURA DE MOSQUITOS*
}

Délsio Natal**

Daniel Marucci**

\begin{abstract}
NATAL, D. \& MARUCCl, D. Aparelho de suç̧̃o tipo aspirador para captura de mosquitos. Rev. Saúde públ., S.Paulo, 18:418-20, 1984.

RESUMO: E feita a descrição de aparelho portátil de suç̧ão tipo aspirador, para captura de mosquitos Culicidae. São sugeridas adaptaçőes para coletas em diferentes situaçōes. São feitos comentários sobre sua aplicação em pesquisa de mosquitos.
\end{abstract}

UNITERMOS: Aparelho de sução. Culicidae, captura. Armadilha de Shannon.

Aparelhos de sucção tipo aspirador são muito empregados em pesquisas de culicídeos. São geralmente destinados a observaçōes sobre abrigos ou à obtenção de fêmeas ingurgitadas para determinação do repasto sanguíneo. Existem vários modelos, que po. dem variar,' entre outras características, no tamanho e potência, indo desde o grande aspirador montado em veículo de Bidling. mayer e Edman ${ }^{1}$ (1967) até pequenos modelos cuja sucção é conseguida com a boca do operador (Burton ${ }^{2}, 1971$; Sholdt e Neri ${ }^{3}$, 1974). Geralmente cada pesquisador adota o modelo que se adapta melhor à área onde desenvolve sua pesquisa. Assim sendo, descreve-se aqui aparelho construído para ser empregado em pesquisa ora em andamento na região do Vale do Ribeira, Estado de São
Paulo, sobre hábitos alimentares de culicídeos.

Um esquema mostrando a secção longi. tudinal do aspirador pode ser visto na Figura. O corpo do aparelho (ca) foi construído a partir de uma luva de PVC de três polegadas. O motor $(m)$ - micro-motor de uso geral de $6.000 \mathrm{rpm}$ - é preso ao corpo do aparelho através de duas alças de suporte (as). Estas são feitas de tiras de alumínio, preparadas para encaixar o motor na parte central. Suas extremidades são dobradas lateralmente e presas por parafusos ao corpo do aparelho. $O$ motor é alimentado por uma bateria de 6 vcc, através dos fios de alimentação (al). Nas extremidades destes fios, existem garras tipo "jacaré" que permitem sua fixação aos terminais da bateria. Para maior conforto, suge-

"Desenvolvido com aux llio financeiro da "National Academy of Sciences" - USA, Convênio nọ MVR-BR-2-84-6.

** Do Departamento de Epidemiologia da Faculdade de Saúde Pública da Universidade de São Paulo Av. Dr. Arnaldo, 715 - 01255 - São Paulo, SP - Brasil. 
NATAL, D. \& MARUCCI, D. Aparelho de sucção tipo aspirador para captura de mosquitos. Rev. Saúde públ., S. Paulo, 18:418-20, 1984.

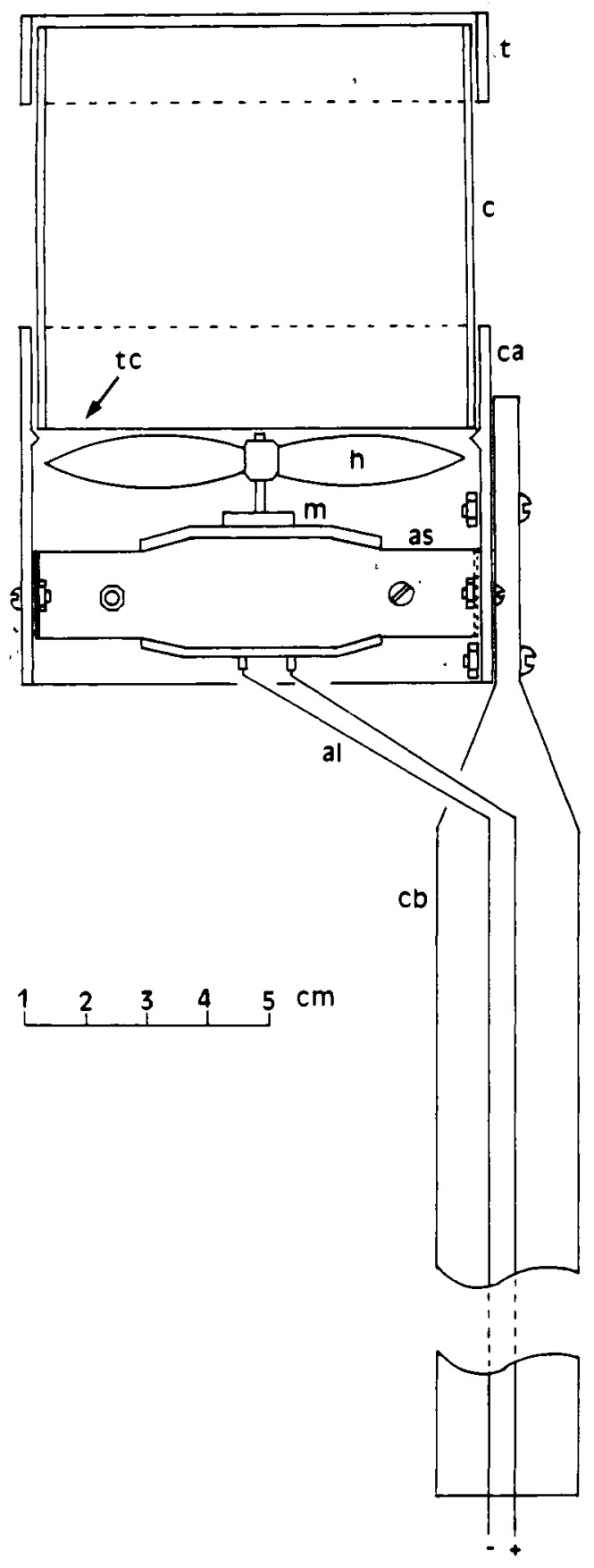

Figura 1 - Seç̧ão longitudinal do aparelho de sucção tipo aspirador. (explicação no texto). re-se transportar a bateria presa a um cinto de couro.

A câmara de captura (c), é construída de tubo PVC de três polegadas; na sua parte in. ferior, existe uma tela fina (tc), que tem por finalidade reter o material aspirado. Sua parte superior, quando em operação, é aberta, permitindo assim que os mosquitos sejam aspirados para o interior da câmara, os quais são mantidos neste compartimento, pelo flu. xo de ar provocado pela hélice (h). Antes de desligar o aparelho, fecha-se a câmara de cap. tura com a tampa $(t)$, construida a partir de luva de PVC de três polegadas e provida de tela fina.

O cabo (cb) foi construído a partir de cano de alumínio com diâmetro de uma polegada, que teve uma das extremidades achatada para permitir sua fixação ao corpo do aparelho. $\mathrm{O}$ comprimento do cabo pode va. riar de acordo com o local de captura. As. sim, cabos longos são próprios para coletas no teto de residèncias, enquanto cabos mais curtos são ideais para trabalho no interior de florestas densas. Também aparelhos sem cabo podem ser utilizados em capturas de isca humana, ou para "limpar" armadilha tipo Shannon.

Este aparelho vem sendo utilizado em coletas de rotina, tendo-se mostrado bastante eficiente em capturas realizadas no intra $e$ peridomicílio, no ambiente aberto e interior de matas. Pode ser empregado em coletas no solo, em troncos de árvores, abrigos de animais e fendas em rochas. Sua aplicação em isca humana é aconselhável pois, nesse caso, torna-se possível capturar o mosquito em vôo, quando o mesmo se aproxima do operador. Em armadilha tipo Shannon, embora não sendo seletivo (coleta também outros insetos devido as dimensōes de sua boca), permite capturar rapidamente os mosquitos, evitando que os mesmos se acumulem nas paredes da armadilha, fato esse que ocorre normalmente nas horas de pico quando se trabalha com tubo de clorofórmio. Este tipo de aspirador tem ainda a vantagem de possuir a câmara de captura em posição anterior à hélice, o que evita a danificação do material coletado. 
NATAL, D. \& MARUCCI, D. Aparelho de sucção tipo aspirador para captura de mosquitos. Rev. Saúde públ., S. Paulo, $18: 418-20,1984$.

NATAL, D. \& MARUCCI, D. [ A "vacuum-cleaner" type of suction apparatus for the collection of mosquitoes]. Rev. Saúde públ., S. Paulo, 18:418-20, 1984.

ABSTRACT: A portable suction apparatus, which functions like a vacuum cleaner used for the collection of Culicidae mosquitoes is described. Adaptations for collecting in differents situations are suggested and some comments about its application in mosquitoes surveys are made.

UNITERMS: Suction apparatus. Culicidae, collection. Shannon trap.

\section{REFERENCIAS BIBLIOGRÄFICAS}

1. BIDLINGMAYER, W. L. \& EDMAN, J. D. Vehicle mounted aspirator. Mosq. News, 27: 407-11, 1967.

2. BURTON, G. J. Insect aspirator made from plastic or glass serological pipettes. Mosq. News, 21: 220, 1971.
3. SHOLDT, L. L. \& NERI, P. Mouth aspir ztor with holding cage for collecting moscuitoes ant other insects. Mosq. News, 34: $236,1974$.

Recebido para pubicaçãō em 09/08/1984. Aprovado para publicação em 17/08/1984. 